\title{
Critical appraisal of stem cell therapy in peripheral arterial disease: Do current scientific breakthroughs offer true promise or false hope?
}

\author{
Sherif Sultan ${ }^{1,2 *}$, Niamh Hynes ${ }^{2}$ \\ ${ }^{1}$ Department of Vascular \& Endovascular Surgery, Western Vascular Institute, University Hospital Galway, Galway, Ireland \\ ${ }^{2}$ Department of Vascular and Endovascular Surgery, Galway Clinic, Doughiska, Galway, Ireland \\ Email: "sherif.sultan@hse.ie
}

Received 31 December 2013; revised 3 February 2014; accepted 10 February 2014

Copyright (C) 2014 Sherif Sultan, Niamh Hynes. This is an open access article distributed under the Creative Commons Attribution License, which permits unrestricted use, distribution, and reproduction in any medium, provided the original work is properly cited. In accordance of the Creative Commons Attribution License all Copyrights (C) 2014 are reserved for SCIRP and the owner of the intellectual property Sherif Sultan, Niamh Hynes. All Copyright (c 2014 are guarded by law and by SCIRP as a guardian.

\section{ABSTRACT}

Over the last forty years in the field of peripheral arterial disease, there has been a plethora of research into cell-based therapies for tissue repair, regeneration and angiogenesis, progressing from protein-based therapies to gene therapies to stem cell research. Initial pre-clinical research successes have given birth to a whole industry, aimed at translating these laboratory hopes into clinical successes. However, heretofore these expected clinical results have failed to materialize, in part due to the lack of attention to the ischaemic desert like tissue and systemically diseased patient into which the stem cells are being implanted. Unsatisfactory clinical outcomes on the treatment of Critical Limb Ischaemia (CLI) have forced researchers to direct their efforts to the less intimidating challenge of claudication and to lower their clinical outcome thresholds from superior to "non-inferior". Major questions on safety and durability have also arisen. What needs to be objectively established is the impact on the net health outcome of these therapies. Infusion or injection for stem cell therapy is still considered experimental and investigational. In this review we examine the clinical evidence for angiogenic therapies, focusing specifically on stem cell trials, in an attempt to answer the question "Is stem cell therapy a failed experiment or will there be light at the end of the tunnel?"

\section{KEYWORDS}

Peripheral Arterial Disease; Stem Cell Therapy; Therapeutic Angiogenesis

"Corresponding author.

\section{INTRODUCTION}

The principal issues for progression of peripheral artery disease (PAD) are endothelium dysfunction and reticence of neovascularization $[1,2]$. Contemporary revascularisation techniques do not pay attention to these core principals, instead they rely primarily on anatomical correction rather than physiological modulation. Regrettably, only $50 \%$ of patients with critical limb ischaemia (CLI) can be managed with contemporary vascular techniques, while satisfactory clinical outcomes are only evident in $25 \%$ of the patients in some vascular centres [3,4]. Although this does not reflect our own experience [5-8], in general such dismal results have driven the quest for more satisfactory and reliable therapies.

Stimulation of neovascularization would seem to be a good alternative therapy for PAD. Research on therapeutic angiogenesis is on-going, whether mechanically by sequential pneumatic compression $[7,8]$, or with the use of cell therapy such as gene delivery of pro-angiogenic growth factors [9-11].

However, most of the positive results on therapeutic angiogenesis over the last four decades have come from animal studies in cardiovascular induced ischemia models. Unfortunately this promise has failed to be realized in human clinical trials, where most of the research has been done on patients with CLI who are not suitable candidates for revascularisation, or the so called "nooption" vascular patient [9]. What has materialized from these clinical trials is a catalogue of technical and safety issues which restrain widespread clinical dissemination both in gene and cell therapy approaches.

Attempts to promote angiogenesis with angiogenic proteins and cell-mobilizing cytokines in the VIVA, 
TRAFFIC and MAGIC trials with vascular endothelial growth factor (VEGF)/fibroblastic growth factor (FGF) and the granulocyte-colony stimulating factors/granulocyte macrophage-colony stimulating factors (G-CSF/GM$\mathrm{CSF}$ ) respectively, failed to promote any vascular regeneration [12-14].

The direct infusion of human recombinant growth factors with/without myoblast transplantation, although promising with early-stage clinical outcomes failed to show sustainable results, which was conceivably secondary to the diminutive half-life of the proteins that were dispensed to the patients.

In order to extend the therapeutic advantage of protein based-therapies, investigators hoped that genetic manipulation may hold the key to a more prolonged benefit of angiogenic growth factors. However gene therapies have yielded very disappointing clinical outcomes. The major issues that have arisen are choice of vector and modulation of the human immune response. The ideal aim of gene therapy would be integrated into host DNA for lifelong expression. Retroviral vectors should be able to facilitate such integration. However retroviral vectors are only taken up by replicating cells resulting in decreased gene transduction. Furthermore, viral vectors, although effective in models of small animals, whose immune system is relatively unsophisticated, induce a more sizeable immune response in human subjects. In order to refine the extent of transgene expression in patients managed by gene therapies, plasmid vectors have been trialed [15,16]. These naked plasmids are minimally immunogenic. However, these episomes are short-lived resulting in low gene transfer into target cell nuclei.

Overall, the stratagem of strengthening expression of a single growth factor has failed to deliver any significant clinical improvement and led researchers to explore the more comprehensive field of stem cell therapy and cellbased approaches to therapeutic neovascularization.

\section{CURRENT CELL THERAPY MYTHS}

At present a few myths exist about stem cell therapies, some of which are false, while others are most certainly based on fact. It is fictional to attest that there is a total ban on stem cell research for CLI in the United States. It is even more of a falsehood to believe that embryonic stem cell research is on the verge of producing cures for serious illnesses such as CLI. The facts are that no such ban on stem cell research for CLI exists, only on embryonic stem cell production and that federal funding has disallowed embryonic stem cell research. However even if embryonic stem cell research was able to be undertaken in the US, there is absolutely no evidence to suggest that embryonic stem cells offer the elixir of life. In fact embryonic stem cells have not helped a single human patient with CLI.
Myths about stem cell therapies and an almost fantastical expectation of their potential benefits have led to troubling craze of "Stem Cell Tourism". Unscrupulous elements in the healthcare sector have used these mythical notions to take advantage of vulnerable patients who anguish from terminal or incurable diseases and have little hope from orthodox medicine. Such patients are willing to travel to stem cell clinics, which purport to offer them therapies, and cures without proven efficacy and where no long-term follow-up is implemented. Patients seeking treatment usually have no options, and their window of time to benefit from therapies is unfortunately short. This stem cell tourism is not only exorbitant but in fact they undermine genuine stem cell research programmes and detract the encouraging areas of cell therapies that are showing perceptible progress.

Legitimate stem cell therapy proponents need to make a concerted effort to temper claims and offer realistic expectations. It requires an honest acknowledgement of prospective therapeutic benefits and timelines.

\section{CONTEMPORARY LITERATURE REVIEW}

There were three randomized placebo-controlled trials in patients with PAD that were conducted to test the effects of angiogenic factors on stimulation of vascular growth, either angiogenesis or angiogenesis/arteriogenesis:

First was the Therapeutic angiogenesis with recombinant fibroblast growth factor-2 for intermittent claudication (TRAFFIC) trial were intra-arterial infusion of fibroblast growth factor-29 used in 190 patients [17]. Second was the Regional Angiogenesis with Vascular Endothelial Growth Factor in peripheral arterial disease (RAVE) trial utilizing intra-muscular injection of adenoviral VEGF 121 gene in 105 patients [18]. Third was the STimulation of ARTeriogenesis using subcutaneuous application of granulocyte-macrophage colony-stimulating factor as a modality in management for PAD (START) trial which used subcutaneously injection of granulocyte-macrophage colony-stimulating factor in 40 patients [19].

None of the above three trials showed any improvement in walking capacity and all three failed to meet the high expectations. In fact these protein-based therapies have been associated with serious adverse side-effects. The effects of protein-based therapy with administration of recombinant basic fibroblast growth factor (bFGF) can be unpredictable. The administration of bFGF has caused increases in formation of collateral vessels in rats and rabbits. However this effect is dose-dependent, and high doses of bFGF have been shown to inhibit angiogenesis and collateral circulation. On the other hand the combined administration of VEGF and bFGF proteins has a synergistic effect on angiogenesis in vivo. This protein-based therapy, when applied to human subjects, has 
been associated with quite pronounced adverse effects especially in the case of bFGF treatment with renal toxicity, proteinuria, anemia and thrombocytopenia reported even with low doses of bFGF. The negative conclusion of the TRAFFIC Study in CLI patients, which demonstrated poor efficacy of bFGF therapy but with significant nephrotoxicity, forced the trial to be abandoned.

The disappointing effects of protein-based therapies encouraged research into a more sophisticated delivery mode for vascular growth-factors. There was initial enthusiasm surrounding the use of local gene therapy for the sustained over-expression of the chosen therapeutic factor in the targeted tissue. Pre-clinical studies gave positive results, but as with protein based-therapies the translation of gene therapy from animal laboratory to human clinical trials was fraught with disappointments. Issues related to transduction efficiency, route of administration, vector type and dose proved to be a challenge.

In the TAMARIS trial [20], the largest trial in its field, phase 3 trials on the use of non-viral 1 FGF (NV1FGF) for critical limb ischaemia failed to deliver in terms of clinical endpoints. 525 patients unsuitable for revascularisation were randomly allocated to intramuscular injections of NV1FGF or placebo. After follow-up of 1 year, the primary endpoint of time to major amputation or death did not differ between the groups. Nor was there a hint of an effect on secondary endpoints, such as ulcer healing, relief of rest pain, functionality or hospital readmission rate, and no differences in treatment effect were seen in subgroups of patients, such as those with diabetes. This was disappointing, because expectations were high after the phase 2 trial, which showed a large reduction in amputations and death in the NV1FGF group [21]. However, differences in this endpoint in phase 2 could have occurred fortuitously, particularly as the trial was small $(n=125)$; the reduction in amputations and death was one of several outcomes, and no difference occurred in the primary endpoint of ulcer healing. What we have learned from clinical trials is that several endogenous and exogenous factors have the potential to effect gene therapy efficacy in individual patients. Patients usually have widespread cardiovascular disease, and angiogenesis might be inhibited by risk factors, such as dyslipidaemia and diabetes [22] (in TAMARIS, 60.4\% of patients had hyperlipidaemia and $53.3 \%$ had diabetes, although no difference in effect was noted in those without diabetes) [21].

Cardiovascular drugs, such as statins (62.5\% of patients in TAMARIS) and angiotensin-converting enzyme inhibitors (51.4\%), might also have inhibited angiogenesis.

What is noteworthy about the TAMARIS phase 3 group is that more patients in the NV1FGF group discontinued their treatment $(n=29(11 \%), 24$ of which were due to adverse events) compared to the placebo group ( $\mathrm{n}=18$ (7\%), 16 of which were due to adverse events). Overall, a higher incidence of treatment-emergent adverse events occurred in the NV1FGF group compared to the placebo group. Significant differences emerged in musculoskeletal and connective tissue disorders (50 [19\%] of 266 vs 25 [10\%] of 257; p = 0.004] mainly represented by pain and discomfort (34 [13\%] of 266 vs 17 [7\%] of 257; p = 0.02). A significantly higher incidence of treatment-related adverse events was also recorded for the metabolism and nutrition disorders (41 [15\%] of 266 versus 19 [7\%] of 257; p = 0.0057). This difference was mainly represented by glucose metabolism disorders (including diabetes mellitus): 20 (8\%) of 266 versus eight $(3 \%)$ of $257 ; p=0.0316$. This trial, which showed no benefit in the use of NV1FGF in CLI, was fully funded by Sanofi-Aventis, Paris, France.

The lack of efficacy and adverse event rate is not only related to genes encoding for FGF. First clinical trials with intravascular delivery of VEGF vector constructs have only resulted in limited benefits to the patients. Second generation VEGF-based gene therapy trials are based on direct intramyocardial and intraskeletal muscle injections in order to achieve better transfection efficiency and more targeted effects. However, oedema and excess non-physiological growth of capillaries in the retina have been detected as adverse effects of the AdVEGF gene therapy and again issues arise related to transduction efficiency, route of administration, vector type, dose and duration of treatment to achieve optimal therapeutic angiogenesis [23].

Overall gene therapy is not proving to be the answer to treatment of peripheral arterial disease its own right. A meta-analysis by Ghosh et al. examined five eligible randomised clinical trials, containing 508 patients and found no significant differences between control and intervention groups for any outcomes, irrespective of whether low-dose or high-dose gene therapy was tried [24]. They concluded that gene therapy confers no benefit on patients with PAD and found on closer examination of the individual trials that several have an excessive placebo response. A more recent meta-analysis by Hammer et al. goes even further. They performed a search to identify RCTs studying local administration of pro-angiogenic growth factors (VEGF, FGF, HGF, Del-1, HIF-1alpha) using plasmid or viral gene transfer by intra-arterial or intra-muscular injections. Their search yielded 12 RCTs with a total of 1494 patients (29\% females), the majority of who were suffering from CLI (64\%). Meta-analysis showed no significant benefit for gene therapy when synthesizing data for all-cause mortality (OR 0.88, 95\% CI 0.62 - 1.26) amputations (OR 0.64, 95\% CI 0.31 - 1.31) or ulcer healing (OR 1.79, 95\% CI 0.8 - 4.01). No differences were seen between patients with intermittent clau- 
dication or CLI [25].

Grochot-Przeczak et al. in their review of clinical trials of therapeutic angiogenesis showed that gene therapy did not produce satisfactory outcomes. On the other hand, cell therapy approaches, despite several limitations, demonstrated more beneficial effects, notwithstanding the fact that initial clinical studies need to be constantly validated by larger randomized, multi-center, double-blinded, placebo-controlled trials [26].

Research into cell-based therapy in PAD has mainly focused on progenitor cells derived from bone marrow or peripheral blood but more recently other cell types are entering clinical trials including mesenchymal stromal cells derived from placenta. As with protein-based and gene therapies, the goal of stem cell therapy is to promote angiogenesis and collateral vessel formation. The first clinical trial of cell therapy for PAD was performed by Tateishi-Yuyama et al. in 2002 (Therapeutic Angiogenesis using Cell Transplantation Study, or TACT) [27]. In this study, injection of Bone Marrow-derived MonoNuclear Cells (BMMNCs) into the gastrocnemius muscle of patients with diabetes and symptomatic PAD resulted in an improvement in ABI, transcutaneous oxygen tension, pain-free walking time, and rest pain. Since that time, numerous other studies have examined the efficacy and safety of cell therapy for PAD, with varying results (Table 1) [27-39].
There are many issues with clinical trials of cell therapy for PAD. Most trials have consisted of uncontrolled patient series, and there is a paucity of randomized, properly controlled studies. Sample sizes have been relatively small, with most studies enrolling fewer than 50 patients. There have been many variables even within the relatively small population group. Varying degrees of PAD severity have been studied, ranging from intermittent claudicants to patients with critical limb ischemia. There has also been variation in the mode of delivery with cells delivered either by direct intramuscular injection at multiple sites of the affected limb or by intra-arterial injection via the femoral artery. The therapeutic product for nearly all of the trials has been BMMNCs and/or peripheral blood-derived mononuclear cells (PBMNC) harvested with or without granulocyte colony-stimulating factor mobilization. Reported endpoints of these studies have included ABI, transcutaneous oxygen tension, and angiography examined at baseline and following cell therapy, with an average follow-up period of approximately 6 months to 1 year. Subjective outcomes have also been reported, including patient-perceived rest pain and pain-free walking time or distance.

Meta-analysis of the 37 clinical trials of autologous stem cell therapy for PAD showed that such an approach is effective in improving surrogate indexes of ischemia,

Table 1. Controlled cell therapy clinical trials for Peripheral Arterial Disease. BMMNC: bone marrow-derived mononuclear cell; G-CSF: granulocyte-colony stimulating factor; PBMNC: peripheral blood-derived mononuclear cell; ABI: ankle-brachial index; $\mathrm{TcPO}_{2}$ : transcutaneous oxygen tension.

\begin{tabular}{|c|c|c|c|c|c|c|c|}
\hline Reference & $\begin{array}{l}\text { Number of } \\
\text { Patients }\end{array}$ & $\begin{array}{c}\text { Number of } \\
\text { Control Patients }\end{array}$ & Type of Cell & Follow-up & ABI & $\mathrm{TcPO}_{2}$ & Limb salvage \\
\hline Tateishi-Yuyama (2002) & 22 & 24 limbs & $\begin{array}{l}\text { BMMNC or BMMNC } \\
\text { and PBMNC }\end{array}$ & 4 and 24 weeks & Improved & Improved & Improved \\
\hline Huang (2005) & 14 & 14 & G-CSF mobilized PBMNC & 3 months & Improved & & Improved \\
\hline Arai (2006) & 13 & 12 & BMMNC & 1 month & Improved & Improved & \\
\hline Bartsch (2007) & 13 & 12 & BMMNC & 2 and 13 months & Improved & & \\
\hline Corbellis (2008) & 10 & 9 & BMMNC & 12 months & Improved & & \\
\hline Prochazka (2010) & 42 & 54 & BMMNC & 4 months & Improved & No Effect & Improved \\
\hline Walter (2011) & 19 & 21 & BMMNC & 3 and 6 months & No Effect & Improved & Improved \\
\hline Iafrati (2011) & 34 & 12 & BMMNC & $1,4,8,12$ weeks & Improved & Improved & Improved \\
\hline Idei (2011) & 51 & 46 & BMMNC & 3 - 4 years & Improved & Improved & Improved \\
\hline Benoit (2011) & 34 & 14 & BMMNC & 6 months & No Effect & & Improved \\
\hline Powell (2011) & 32 & 14 & Expanded BMMNC & 6 months & No Effect & & Improved \\
\hline Powell (2012) & 48 & 24 & $\begin{array}{c}\text { Expanded, multicellular } \\
\text { therapy }\end{array}$ & 12 months & & & Improved \\
\hline Losordo (2012) & 16 & 12 & Enriched CD34 + BMMNC & 6 and 12 months & No Effect & & Improved \\
\hline
\end{tabular}


subjective symptoms and hard endpoints (ulcer healing and amputation) [40]. On the contrary they found that granulocyte colony stimulating factor (G-CSF) monotherapy was not associated with significant improvement in the same endpoints. The authors concluded that intramuscular autologous bone marrow cell therapy is a feasible, relatively safe and potentially effective therapeutic strategy for PAD patients, who are not candidate for traditional revascularization but with the caveat that larger, placebo-controlled, randomized multicenter trials have not yet been planned and conducted to confirm these findings.

\section{ISSUES WITH STEM CELL THERAPIES}

\subsection{Patient Population}

Several limitations to stem cell therapy have already emerged, even within the limited catalogue of clinical research properly conducted within the field. First and foremost, it has been established from reality early on that patients who require treatments for PAD are most often elderly, which affects the population of angiogenic Bone Marrow Derived Cells (MDCs) and/or Peripheral Blood Derived Cells (PBDCs). In addition, ischemic diseases are usually accompanied by diabetes, hypertension, renal failure and hypercholesterolemia, which further influence the reduction in the number of progenitor cells and impair their function $[27,41]$.

\subsection{Pathophysiology and Disease Severity}

Multivariate Analysis from the TACT trial demonstrated that the severity of rest pain and the presence of a failed lower limb bypass graft were both negative prognostic factors affecting amputation free survival. These finds are in conflict with research findings which demonstrate the positive effects on angiogenesis of cytokines produced by the ischemic limbs, such as IL- $1 \beta$, which have been shown to enhance the function of BM-MNCs postimplantation [42,43]. The results from TACT and other trials demonstrating the poor outcomes in CLI, raise the question of the actual mode of action of stem cell therapy. Gupta et al. in their double-blinded placebo-controlled randomized trial on patients with CLI found that the placebo group performed better that those treated with intramuscular Bone Marrow derived allogenic stem cells. Out of 7 in the allogenic BM stem cell group, two died within 30 days and 2 had a major amputation. On the other hand rest pain was ameliorated in all of the placebo group in the first quarter but in none of the stem cell therapy group [44].

The adverse outcomes in failed bypass surgeries are somewhat easier to understand than in primary interventions for CLI, since in the case of redo bypass surgery the network of preexisting collateral vessels are blocked and so this negatively affects the neo-capillary development from collateral vessels.

Adverse outcomes with CLI have led some investigators to concentrate on claudication. By the time phase 3 of the TACT study was underway, the trial had deviated from being one focused on "no option" patients to one which included patients with Fontaine class III, i.e. very mild, PAD [45]. This shift in patient population skewed the results towards non-significance. The TAM-PAD trial evaluated cell therapy in 13 mild claudicant patients and the investigators concluded that the reason for improvement in augmented neo-angiogenesis is the combined intra arterial and intra muscular injection [30]. Their hypothesis for this synergistic effect of intra-arterial and intra-muscular injection is that stem cells in themselves cannot build new vessels; rather they function as conductors for monocyte cells by secreting cytokines and chemokines. However a more objective analysis of these results might attribute any benefits seen in the treatment group to the fact that they had relatively mild disease. The natural history of claudication is that only $5 \%$ of these patients will ever progress to CLI. Improvements in claudicants cannot be attributed to stem cell therapy without allowing for the contribution of simple therapeutic measures such as exercise, medical therapy and smoking cessation.

More significant perhaps than the differences between claudication and critical limb ischaemia is the fact that many trials have included patients with Thromboangiitis Obliterans. The pathophysiology and patient population affected by TAO, which is an inflammatory condition affecting small and medium sized arteries and directly related to smoking, is at great variance with that of Peripheral arterial occlusive disease and therapies to treat these diseases should not be assessed within the same trial. In the TACT trial, the survival rate in patients with atherosclerotic PAD was $80 \%$ as compared to $100 \%$ in Patients with Thromboangiitis Obliterans, while the amputation survival free survival rate was $60 \%$ in Patients with PAD versus $91 \%$ in Thromboangiitis Obliterans patients. Benefits seen in TAO patients cannot be attributed to stem cell therapy without accounting for the confounding factor of smoking cessation. Similarly in the PROVASA trial they used intra-arterial BM-MNC but it did not increase ankle brachial indices in CLI patients even with repeated administration of functionally competent BM-MNC, and while critically ischaemic patients with gangrene and impending amputation did not derive any benefit form BM-MNC, those patients with TAO responded positively [33]. 


\section{CELL THERAPY DELIVERY; THE FUTURE}

Stem cell research is in its infancy and there are many questions to be answered before we can hope that this treatment option will provide acceptable clinical outcomes and sustainable results.

\subsection{Which Stem Cell?}

Stem cell research has focused, until recently, on two broad categories of stem cells, the Embryonic Stem Cell (ESC) and the adult stem cell. The ESC is derived from the inner cell mass of the fetal blastula and its pluripotency means that it has the ability to differentiate into any cell type found in the adult body. ESCs can replicate via mitotic division while retaining their undifferentiated state (self-renewal) or differentiate into lineage-specific cells under the appropriate stimuli. ESCs have a much greater proliferative capacity than adult stem cells but their clinical use remains conflicted by the ethical debate surrounding the use of human embryos. Furthermore, cells derived from ESCs will be allogeneic, and therefore an immunological barrier exists which is likely to require the coadministration of immunosuppressive agents, which carry their own substantial risks. Additionally, the great regenerative potential of these cells has raised fears about the administration of even a single pluripotent ESC. The undirected growth and pathological differentiation after transplantation of an ESC creates a substantial risk of teratoma, and this complication remains a lifelong risk that can occur late after administration [46]. The considerable risk associated with these stem cells requires much more robust differentiation and purification protocols, and studies proving the long-term safety profile of embryonic progenitors before widespread use in humans will be possible.

In contrast to ESCs, adult stem cells have the capacity to give rise only to cells of a given germ layer because they are partially lineage committed. In other words, they are multipotent rather than pluripotent. All adult stem cells, whether harvested from the marrow, blood, or resident tissue, share a number of characteristics that make them attractive. The first is that these cells are harvested from the patient in whom they are ultimately to be used and do not need to overcome an immunologic barrier. Adult stem cells, and EPCs in particular, have undergone the most translational and human studies of all stem cell approaches, even though robust clinical data is still scarce. Some of the issues which have arisen with the use of adult stem cells include delays in stem cell processing. The use of autologous cells, although attractive in terms of immunological response, lends itself to delays in treatment because of the time needed to collect the cells and isolate and then propagate progenitors ex vivo so as to obtain sufficient numbers before injection. Adverse effects of their delivery could include microvascular embolism, especially in diabetic patients, as well as unintended acceleration of pathological neovascularization, as in the case of an occult malignancy.

Furthermore, methods of specifically identifying stem cells such as EPCs are poorly defined. Reproducible and efficient methods to isolate, expand, and deliver angiogenic cells are needed. In addition, it is not known what combination of progenitor cells might be most therapeutic in humans, e.g., purified EPCs, adipose tissue, or even some combination with smooth muscle precursors and/or subsets of hematopoietic progenitors [47-51]. In other to maximise on adult stem cell therapies the mechanisms by which these adult stem cells interact to confer benefit must be further defined so that they can be manipulated therapeutically.

Further limitations exist in the use of adult stem cells. For example with EPCs, in the patients who most need EPC therapy, these cells are scarce, have restricted replicative capacity, and are often dysfunctional. People with vascular disease are ostensibly older and EPCs derived from older individuals have been shown in preclinical models to have an impaired ability to proliferate, incorporate into existing capillary networks, and enhance limb perfusion. In addition to age, other conditions typically associated with vascular disease, such as diabetes mellitus, impair angiogenic functionality [52,53].

These issues with autologous stem cell harvesting have raised the question of allogenic sources of stem cell. However in order for this to be feasible allogeneic stem cell must lack both, major histocompatibility complex antigens and various costimulatory cell surface antigens and more trials to be performed with allogeneic stem cells for further evaluation of their safety and feasibility [54]. Long-term immune suppression is undesirable, as it poses extreme risks for infection, development of malignancies, and patient well-being. However it was shown that expanded cultured purified hematopoietic stem cells were effective in establishing allogeneic chimerism when transplanted across major histocompatibility complex barriers. It is possible to expand regulatory natural T-cells (CD4+, CD25+) for transplantation tolerance and the treatment of autoimmunity. These developments could lead to effective tolerance strategies based on T-cell tolerance

\subsection{Induced Pluripotent Stem Cells}

Scientific interest has shifted to a newly described class of stem cell, the induced pluripotent stem cell (iPSC). iPSCs are derived from terminally differentiated adult somatic cells that are "reprogrammed" to an embryoniclike state with transcription factors that govern cell differentiation. Interest in iPSCs is high because these cells 
are autologous (do not require immunosuppression when delivered), have pluripotential (can differentiate into tissue from each of the 3 germline lineages), are noncontroversial (are derived from adult tissue), and come from a plentiful source (are derived from any adult cell [e.g., skin fibroblasts, adipose tissue, hair etc.]) [55].

However, a number of obstacles need to be overcome in the clinical development of these cells. The combination of gene manipulation with cell therapy raises safety concerns and regulatory barriers. For example, the use of retroviruses or lentiviruses leads to integration of viral DNA into the chromosome, which carries the risk of silencing indispensable genes or inducing oncogenesis [56]. These concerns are overcome in part with the use of adenoviruses or plasmid constructs [57-59], but even these episomal vectors carry a risk of DNA integration.

Manufacturing hurdles also need to be overcome prior to therapeutic application. Animal products or nonhuman iPSC feeder cells used to generate and passage cells will need to be replaced by defined media and matrices to avoid immune responses to animal protein and to obviate the risk of xenotransmission of zoonotic infections [60, 61]. Furthermore, current reprogramming methods are extremely inefficient. The induction of iPSCs from human fibroblasts takes weeks (generally 3 to 4 weeks) [62], and the yield is low (approx. $0.01 \%$ to $0.1 \%$ ) [56].

\subsection{Adjuvant Therapies}

Areas of stem cell research requiring attention include identification of effective cell populations; refinement of isolation and processing methods; a deeper understanding of the features that defines potency; establishment of the optimal delivery method; tailoring of the timing and dosing regimens to the disease state and clinical trajectory. Adjunctive therapies will need to be developed to overcome endogenous impairments in EPC function and to enhance vascular responsiveness to stem cell therapy. One area that remains to be explored is the possible synergy of macrovascular revascularization with efforts to restore microvascular circulation.

In effect what needs to be explored is the harnessing of the body's innate ability to repair by provision of the necessary growth factors and appropriate cytokines. Tatard et al. explored this issue, suggesting that stem cell therapy limitations can be resolved by simulating proliferation of cells that are normally quiescent and are physiologically involved in the regenerative process in ischemic tissues to steer the physiological repair process. However cytokines and growth factors that are injected into the lesions quickly disappear from the site of injection because they are removed by the blood flow and degraded by specific enzymes located in the extracellular microenvironment. To overcome this drawback, and issues with cell survival, lack of cell differentiation and integration in the host tissue, pharmacologically active microcarriers (PAM), which are biodegradable particles made with poly(D,L-lactic-co-glycolic acid) (PLGA) and coated with adhesion molecules have been developed. The aim of these PAM is to serve as a support for cell culture and may be used as cell carriers presenting a controlled delivery of active protein. They can thus support the survival and differentiation of the transported cells as well as their microenvironment [63]. This futuristic concept of bioengineered microspheres or nanascaffolds that can prolong, recruit and improve regenerative activities of bioactive factors and resident stem cells is very exciting but not something which will be realized in the near future and far from a clinical reality $[64,65]$.

\subsection{Infrastructure for Research and Development}

In order to develop cell-based therapies and address the multitude of obstacles that occur to the clinical dissemination of these treatments, then well-structured and highly specialized clinical research facilities are required. In their article entitled "The Alpha Stem Cell Clinic: A Model for Evaluating and Delivering Stem Cell-Based Therapies”, Trounson et al. provide an insight into the requirements for future development of the stem cell industry [66]. They address the reluctance of industry to commit too heavily to a technology which is so immature and as of yet largely unproven in clinical terms. This is especially true of pharmaceutical and medtech industries, which are constrained by the regulatory obligations and understand the massive financial commitment of clinical trials. They also highlight concerns over stem cell tourism and emphasise the need to provide evidence of safety and efficacy as a mandatory step to advance this field. The authors propose the establishment of alpha stem cell clinics which involve a carefully constructed cell therapy clinical infrastructure with the requisite scientific, technical, and medical expertise and operational efficiencies. These centres will have the capabilities to address three fundamental and critical functions: 1) fostering clinical trials; 2) evaluating and establishing safe and effective therapies, and 3) developing and maintaining the delivery of therapies approved by the Food and Drug Administration, or other regulatory agencies. To achieve these goals, alpha stem cell centres require links with translational researchers; highly qualified clinicans with disease expertise; expertise in handling, delivery and monitoring of cell therapies; Clinical trial expertise; patient safeguards of medical standards, ethical oversight and review boards, data and safety monitoring; laboratory and personnel with key technical expertise; informatics infrastructure for long-term storage of confidential data; capacity to collect long term, longitudinal data on safety and efficacy of the cell therapy; Educational outreach to patients and their 
caregivers; appropriate licensing of cell therapies and a sustainable business model capable of generating subsidiary Beta clinics.

\section{CONCLUSION}

Preclinical studies demonstrating spectacular efficiency of angiogenic therapy have not translated into real-life clinical outcomes. Disappointing results from clinical trials have forced investigators to readjust their markers of success. Having once envisaged a therapy that could salvage the limbs of CLI patients, investigators now report more wholly outcomes for patients with less severe disease, such as mild claudication, or worse still some investigators have now taken the stance of "non-inferiority" as a get-out clause when justifying a less favorable outcome than expected from their expensive trials. As celltherapy research and clinical trials progress, a standard of reporting needs to be established so that we can differentiate between the natural history of this progressive disease and cell therapy outcomes via vascular repair and regeneration. Until such time, we shall be witnessing more newspaper articles than clinical trial publications.

\section{REFERENCES}

[1] Behrendt, D. and Ganz, P. (2002) Endothelial function. From vascular biology to clinical applications. American Journal of Cardiology, 90, 40L-48L. http://dx.doi.org/10.1016/S0002-9149(02)02963-6

[2] Ferrara, N. (2002) Role of vascular endothelial growth factor in physiologic and pathologic angiogenesis: Therapeutic implications. Seminars in Oncology, 29, 10-14. http://dx.doi.org/10.1016/S0093-7754(02)70064-X

[3] Bradbury, A.W., Adam, D.J., Bell, J., Forbes, J.F., Fowkes, F.G., Gillespie, I., Ruckley, C.V. and Raab, G.M. (2010) BASIL trial Participants. BASIL trial Bypass versus Angioplasty in Severe Ischaemia of the Leg (BASIL) trial: Analysis of amputation free and overall survival by treatment received. Journal of Vascular Surgery, 51, 18S31S. http://dx.doi.org/10.1016/j.jvs.2010.01.074

[4] Kawamoto, A., Katayama, M., Handa, N., Kinoshita, M., Takano, H., Horii, M., Sadamoto, K., Yokoyama, A., Yamanaka, T., Onodera, R., Kuroda, A., Baba, R., Kaneko, Y., Tsukie, T., Kurimoto, Y., Okada, Y., Kihara, Y., Morioka, S., Fukushima, M. and Asahara, T. (2009) Intramuscular transplantation of G-CSF-mobilized CD34(+) cells in patients with critical limb ischemia: A phase I/IIa, multicenter, single-blinded, dose-escalation clinical trial. Stem Cells, 27, 2857-2864. http://dx.doi.org/10.1002/stem.207

[5] Sultan, S. and Hynes, N. (2009) Five-year Irish trial of CLI patients with TASC II type C/D lesions undergoing subintimal angioplasty or bypass surgery based on plaque echolucency. Journal of Endovascular Therapy, 16, 270283. http://dx.doi.org/10.1583/08-2581.1

[6] Sultan, S., Tawfick, W. and Hynes, N. (2013) Cool excimer laser-assisted angioplasty (CELA) and tibial balloon angioplasty (TBA) in management of infragenicular arterial occlusion in critical lower limb ischemia (CLI). Vascular and Endovascular Surgery, 47, 179-191. http://dx.doi.org/10.1177/1538574413478473

[7] Sultan, S., Hamada, N., Soylu, E., Fahy, A., Hynes, N. and Tawfick, W. (2011) Sequential compression biomechanical device in patients with critical limb ischemia and nonreconstructible peripheral vascular disease. Journal of Vascular Surgery, 54, 440-446.

http://dx.doi.org/10.1016/j.jvs.2011.02.057

[8] Tawfick, W.A., Hamada, N., Soylu, E., Fahy, A., Hynes, N. and Sultan, S. (2013) Sequential compression biomechanical device versus primary amputation in patients with critical limb ischemia. Vascular and Endovascular Surgery, 47, 532-539. http://dx.doi.org/10.1177/1538574413499413

[9] Hammer, A. and Steiner, S. (2013) Gene therapy for therapeutic angiogenesis in peripheral arterial disease-A systematic review and meta-analysis of randomized, controlled trials. Vasa, 42, 331-339.

http://dx.doi.org/10.1024/0301-1526/a000298

[10] Sen, S., Conroy, S., Hynes, S.O., McMahon, J., O’Doherty, A., Bartlett, J.S., Akhtar, Y., Adegbola, T., Connolly, C.E., Sultan, S., Barry, F., Katusic, Z.S. and O’Brien, T. (2008) Gene delivery to the vasculature mediated by lowtitre adeno-associated virus serotypes 1 and 5. The Journal of Gene Medicine, 10, 143-151. http://dx.doi.org/10.1002/jgm.1133

[11] Stocca, A., O’Toole, D., Hynes, N., Hynes, S.O., Mashayekhi, K., McGinley, L., O’Connell, E., Coleman, C., Sultan, S., Duffy, A., Tunev, S. and O’Brien, T. (2012) A role for MRP8 in in stent restenosis in diabetes. Atherosclerosis, 221, 325-332. http://dx.doi.org/10.1016/j.atherosclerosis.2012.01.036

[12] Henry, T.D., Annex, B.H., McKendall, G.R., Azrin, M.A., Lopez, J.J., Giordano, F.J., Shah, P.K., Willerson, J.T., Benza, R.L., Berman, D.S., Gibson, C.M., Bajamonde, A., Rundle, A.C., Fine, J. and McCluskey, E.R. (2003) VIVA Investigators. The VIVA trial: Vascular Endothelial Growth Factor in Ischemia for Vascular Angiogenesis. Circulation, 107, 1359-1365. http://dx.doi.org/10.1161/01.CIR.0000061911.47710.8A

[13] Lederman, R.J., Mendelsohn, F.O., Anderson, R.D., Saucedo, J.F., Tenaglia, A.N., Hermiller, J.B., Hillegass, W.B., Rocha-Singh, K., Moon, T.E., Whitehouse, M.J. and Annex, B.H. (2002) TRAFFIC Investigators. Therapeutic Angiogenesis with Recombinant Fibroblast Growth Factor-2 for Intermittent Claudication (the TRAFFIC study): A randomised trial. Lancet, 359, 2053-2058. http://dx.doi.org/10.1016/S0140-6736(02)08937-7

[14] Menasché, P., Alfieri, O., Janssens, S., McKenna, W., Reichenspurner, H., Trinquart, L., Vilquin, J.T., Marolleau, J.P., Seymour, B., Larghero, J., Lake, S., Chatellier, G., Solomon, S., Desnos, M. and Hagège, A.A. (2008) The Myoblast Autologous Grafting in Ischemic Cardiomyopathy (MAGIC) trial: First randomized placebocontrolled study of myoblast transplantation. Circulation, 117, 1189-1200. http://dx.doi.org/10.1161/CIRCULATIONAHA.107.7341 $\underline{03}$ 
[15] Kastrup, J., Jørgensen, E., Rück, A., Tägil, K., Glogar, D., Ruzyllo, W., Bøtker, H.E., Dudek, D., Drvota, V., Hesse, B., Thuesen, L., Blomberg, P., Gyöngyösi, M. and Sylvén, C. (2005) Euroinject One Group. Direct intramyocardial plasmid vascular endothelial growth factor-A165 gene therapy in patients with stable severe angina pectoris: A randomized double-blind placebo-controlled study: The Euroinject One trial. Journal of the American College of Cardiology, 45, 982-988. http://dx.doi.org/10.1016/j.jacc.2004.12.068

[16] Kusumanto, Y.H., van Weel, V., Mulder, N.H., Smit, A.J., van den Dungen, J.J., Hooymans, J.M., Sluiter, W.J., Tio, R.A., Quax, P.H., Gans, R.O., Dullaart, R.P. and Hospers, G.A. (2006) Treatment with intramuscular vascular endothelial growth factor gene compared with placebo for patients with diabetes mellitus and critical limb ischemia: A double-blind randomized trial. Human Gene Therapy, 17, 683-691. http://dx.doi.org/10.1089/hum.2006.17.683

[17] Lederman, R.J., Mendelsohn, F.O., Anderson, R.D., et al. (2002) Therapeutic angiogenesis with recombinant fibroblast growth factor-2 for intermittent claudication (the TRAFFIC study): A randomised trial. Lancet, 359, 20532058. http://dx.doi.org/10.1016/S0140-6736(02)08937-7

[18] Rajagopalan, S., Mohler III, E.R., Lederman, R.J., et al. (2003) Regional angiogenesis with vascular endothelial growth factor in peripheral arterial disease. Circulation, 108, 1933-1938. http://dx.doi.org/10.1161/01.CIR.0000093398.16124.29

[19] Royen, N., Schirmer, S.H., Atasever, B., et al. (2005) START Trial: A pilot study on stimulation of arteriogenesis using subcutaneous application of granulocytemacrophage colony-stimulating factor as a new treatment for peripheral vascular disease. Circulation, 112, 10401046. http://dx.doi.org/10.1161/CIRCULATIONAHA.104.5295 $\underline{52}$

[20] Belch, J., Hiatt, W.R., Baumgartner, I., Driver, I.V., Nikol, S., Norgren, L. and Van Belle, E. (2011) TAMARIS Committees and Investigators. Effect of fibroblast growth factor NV1FGF on amputation and death: A randomised placebo-controlled trial of gene therapy in critical limb ischaemia. Lancet, 377, 1929-1937. http://dx.doi.org/10.1016/S0140-6736(11)60394-2

[21] Nikol, S., Baumgartner, I., Van Belle, E., Diehm, C., Visoná, A., Capogrossi, M.C., Ferreira-Maldent, N., Gallino, A., Wyatt, M.G., Wijesinghe, L.D., Fusari, M., Stephan, D., Emmerich, J., Pompilio, G., Vermassen, F., Pham, E., Grek, V., Coleman, M. and Meyer, F. (2008) TALISMAN 201 investigators. Therapeutic angiogenesis with intramuscular NV1FGF improves amputation-free survival in patients with critical limb ischemia. Molecular Therapy, 16, 972-978. http://dx.doi.org/10.1038/mt.2008.33

[22] Collinson, D.J. and Donnelly, R. (2004) Therapeutic angiogenesis in peripheral arterial disease: Can biotechnology produce an effective collateral circulation? European Journal of Vascular and Endovascular Surgery, 28, 9-23. http://dx.doi.org/10.1016/j.ejvs.2004.03.021

[23] Ylä-Herttuala, S. (2013) Cardiovascular gene therapy with vascular endothelial growth factors. Gene, 525, 217-

\section{9. http://dx.doi.org/10.1016/j.gene.2013.03.051}

[24] Ghosh, R., Walsh, S.R., Tang, T.Y., Noorani, A. and Hayes, P.D. (2008) Gene therapy as a novel therapeutic option in the treatment of peripheral vascular disease: Systematic review and meta-analysis. International Journal of Clinical Practice, 62, 1383-1390.

http://dx.doi.org/10.1111/j.1742-1241.2008.01842.x

[25] Hammer, A. and Steiner, S. (2013) Gene therapy for therapeutic angiogenesis in peripheral arterial disease-A systematic review and meta-analysis of randomized, controlled trials. Vasa, 42, 331-339.

http://dx.doi.org/10.1024/0301-1526/a000298

[26] Grochot-Przeczek, A., Dulak, J. and Jozkowicz, A. (2013) Therapeutic angiogenesis for revascularization in peripheral artery disease. Gene, 525, 220-228.

http://dx.doi.org/10.1016/j.gene.2013.03.097

[27] Tateishi-Yuyama, E., Matsubara, H., Murohara, T., Ikeda, U., Shintani, S., Masaki, H., et al. (2002) Therapeutic angiogenesis for patients with limb ischaemia by autologous transplantation of bone-marrow cells: A pilot study and a randomised controlled trial. Lancet, 360, 427-435. http://dx.doi.org/10.1016/S0140-6736(02)09670-8

[28] Huang, P., Li, S., Han, M., Xiao, Z., Yang, R. and Han, Z.C. (2005) Autologous transplantation of granulocyte colony-stimulating factor-mobilized peripheral blood mononuclear cells improves critical limb ischemia in diabetes. Diabetes Care, 28, 2155-2160.

http://dx.doi.org/10.2337/diacare.28.9.2155

[29] Arai, M., Misao, Y., Nagai, H., Kawasaki, M., Nagashima, K., Suzuki, K., et al. (2006) Granulocyte colonystimulating factor: A noninvasive regeneration therapy for treating atherosclerotic peripheral artery disease. Circulation Journal, 70, 1093-1098. http://dx.doi.org/10.1253/circj.70.1093

[30] Bartsch, T., Brehm, M., Zeus, T., Kögler, G., Wernet, P. and Strauer, B.E. (2007) Transplantation of autologous mononuclear bone marrow stem cells in patients with peripheral arterial disease (the TAM-PAD study). Clinical research in cardiology: Official journal of the German Cardiac Society, 96, 891-899. http://dx.doi.org/10.1007/s00392-007-0569-x

[31] Cobellis, G., Silvestroni, A., Lillo, S., Sica, G., Botti, C., Maione, C., Schiavone, V., Rocco, S., Brando, G. and Sica, V. (2008) Long-term effects of repeated autologous transplantation of bone marrow cells in patients affected by peripheral arterial disease. Bone Marrow Transplantation, 42, 667-672. http://dx.doi.org/10.1038/bmt.2008.228

[32] Procházka, V., Gumulec, J., Jaluvka, F., Salounová, D., Jonszta, T., Czerný, D., Krajča, J., Urbanec, R., Klement, P., Martinek, J. and Klement, G.L. (2010) Cell therapy, a new standard in management of chronic critical limb ischemia and foot ulcer. Cell Transplantation, 19, 1413-1424. http://dx.doi.org/10.3727/096368910X514170

[33] Walter, D.H., Krankenberg, H., Balzer, J.O., Kalka, C., Baumgartner, I., Schlüter, M., Tonn, T., Seeger, F., Dimmeler, S., Lindhoff-Last, E. and Zeiher, A.M. (2011) Intraarterial administration of bone marrow mononuclear cells in patients with critical limb ischemia: A randomized-start, placebo-controlled pilot trial (PROVA-SA). 
Circulation: Cardiovascular Interventions, 4, 26-37. http://dx.doi.org/10.1161/CIRCINTERVENTIONS.110.9 $\underline{58348}$

[34] Iafrati, M.D., Hallett, J.W., Geils, G., Pearl, G., Lumsden, A., Peden, E., Bandyk, D., Vijayaraghava, K.S., Radhakrishnan, R., Ascher, E., Hingorani, A. and Roddy, S. (2011) Early results and lessons learned from a multicenter, randomized, double-blind trial of bone marrow aspirate concentrate in critical limb ischemia. Journal of Vascular Surgery, 54, 1650-1658. http://dx.doi.org/10.1016/j.jvs.2011.06.118

[35] Idei, N., Soga, J., Hata, T., Fujii, Y., Fujimura, N., Mikami, S., Maruhashi, T., Nishioka, K., Hidaka, T., Kihara, Y., Chowdhury, M., Noma, K., Taguchi, A., Chayama, K., Sueda, T. and Higash, Y. (2011) Autologous bone-marrow mononuclear cell implantation reduces long-term major amputation risk in patients with critical limb ischemia: A comparison of atherosclerotic peripheral arterial disease and Buerger disease. Circulation: Cardiovascular Interventions, 4, 15-25.

http://dx.doi.org/10.1161/CIRCINTERVENTIONS.110.9 $\underline{55724}$

[36] Benoit, E., O’Donnell Jr., T.F., Iafrati, M.D., Asher, E., Bankyk, D.F., Hallett, J.W., Lumsden, A.B., Pearl, G.J., Roddy, S.P., Vijayaraghavan, K. and Patel, A.N. (2011) The role of amputation as an outcome measure in cellular therapy for critical limb ischemia: Implications for clinical trial design. Journal of Translational Medicine, 9, 165.

[37] Powell, R.J., Comerota, A.J., Berceli, S.A., Guzman, R., Henry, T.D., Tzeng, E., et al. (2011) Interim analysis results from the RESTORE-CLI, a randomized, doubleblind multicenter phase II trial comparing expanded autologous bone marrow-derived tissue repair cells and placebo in patients with critical limb ischemia. Journal of Vascular Surgery, 54, 1032-1041. http://dx.doi.org/10.1016/j.jvs.2011.04.006

[38] Powell, R.J., Marston, W.A., Bercell, S.A., Guzman, R., Henry, T.D., Longcore, A.T., Stern, T.P., Watling, S. and Bartel, R.L. (2012) Cellular therapy with Ixmyelocel-T to treat critical limb ischemia: The randomized, double-blind, placebo-controlled RESTORE-CLI trial. Molecular Therapy, 20, 1280-1286.

http://dx.doi.org/10.1038/mt.2012.52

[39] Losordo, D.W., Kibbe, M.R., Mendelsohn, F., Marston, W., Driver, V.R., Sharafuddin, M., et al. (2012) A randomized, controlled pilot study of autologous CD34+ cell therapy for critical limb ischemia. Circulation: Cardiovascular Interventions, 5, 821-830. http://dx.doi.org/10.1161/CIRCINTERVENTIONS.112.9 $\underline{68321}$

[40] Fadini, G.P., Agostini, C. and Avogaro, A. (2010) Autologous stem cell therapy for peripheral arterial disease metaanalysis and systematic review of the literature. Atherosclerosis, 209, 10-17.

http://dx.doi.org/10.1016/j.atherosclerosis.2009.08.033

[41] Sekiguchi, H., Ii, M. and Losordo, D.W. (2009) The relative potency and safety of endothelial progenitor cells and unselected mononuclear cells for recovery from myocardial infarction and ischemia. Journal of Cellular Physiology, 219, 235-242. http://dx.doi.org/10.1002/jcp.21672
[42] Tateno, K., Minamino, T., Toko, H., Akazawa, H., Shimizu, N., Takeda, S., Kunieda, T., Miyauchi, H., Oyama, T., Matsuura, K., Nishi, J., Kobayashi, Y., Nagai, T., Kuwabara, Y., Iwakura, Y., Nomura, F., Saito, Y. and Komuro, I. (2006) Critical roles of muscle-secreted angiogenic factors in therapeutic neovascularization. Circulation Research, 98, 1194-1202.

http://dx.doi.org/10.1161/01.RES.0000219901.13974.15

[43] Amano, K., Okigaki, M., Adachi, Y., Fujiyama, S., Mori, Y., Kosaki, A., Iwasaka, T. and Matsubara, H. (2004) Mechanism for IL- $1 \beta$-mediated neovascularization unmasked by IL- $1 \beta$ knock-out mice. Journal of Molecular and Cellular Cardiology, 36, 469-480. http://dx.doi.org/10.1016/j.yjmcc.2004.01.006

[44] Gupta, P.K., Chullikana, A., Parakh, R., Desai, S., Das, A., Gottipamula, S., Krishnamurthy, S., Anthony, N., Pherwani, A. and Majumdar, A.S. (2013) A double blind randomized placebo controlled phase I/II study assessing the safety and efficacy of allogeneic bone marrow derived mesenchymal stem cell in critical limb ischemia. Journal of Translational Medicine, 11, 143. http://dx.doi.org/10.1186/1479-5876-11-143

[45] Matoba, S., Tatsumi, T., Murohara, T., Imaizumi, T., Katsuda, Y., Ito, M., Saito, Y., Uemura, S., Suzuki, H., Fukumoto, S., Yamamoto, Y., Onodera, R., Teramukai, S., Fukushima, M. and Matsubara, H. (2008) TACT Followup Study Investigators. Long-term clinical outcome after intramuscular implantation of bone marrow mononuclear cells (Therapeutic Angiogenesis by Cell Transplantation [TACT] trial) in patients with chronic limb ischemia. American Heart Journal, 156, 1010-1018. http://dx.doi.org/10.1016/j.ahj.2008.06.025

[46] Blum, B. and Benvenisty, N. (2008) The tumorigenicity of human embryonic stem cells. Advances in Cancer Research, 100, 133-158. http://dx.doi.org/10.1016/S0065-230X(08)00005-5

[47] Barber, C.L. and Iruela-Arispe, M.L. (2006) The everelusive endothelial progenitor cell: Identities, functions and clinical implications. Pediatric Research, 59, 26R-32R. http://dx.doi.org/10.1203/01.pdr.0000203553.46471.18

[48] Brixius, K., Funcke, F., Graf, C. and Bloch, W. (2006) Endothelial progenitor cells: A new target for the prevention of cardiovascular diseases. European Journal of Preventive Cardiology, 13, 705-710. http://dx.doi.org/10.1097/01.hjr.0000221862.34662.31

[49] Gimble, J.M., Katz, A.J. and Bunnell, B.A. (2007) Adipose-derived stem cells for regenerative medicine. Circulation Research, 100, 1249-1260. http://dx.doi.org/10.1161/01.RES.0000265074.83288.09

[50] Loffredo, F. and Lee, R.T. (2008) Therapeutic vasculogenesis: It takes two. Circulation Research, 103, 128-130. http://dx.doi.org/10.1161/CIRCRESAHA.108.180604

[51] Roche, R., Hoareau, L., Mounet, F. and Festy, F. (2007) Adult stem cells for cardiovascular diseases: The adipose tissue potential. Expert Opinion on Biological Therapy, 7, 791-798. http://dx.doi.org/10.1517/14712598.7.6.791

[52] Asahara, T. and Kawamoto, A. (2004) Endothelial progenitor cells for postnatal vasculogenesis. American Journal of Physiology-Cell Physiology, 287, C572-C579. 
http://dx.doi.org/10.1152/ajpcell.00330.2003

[53] Spinetti, G., Kraenkel, N., Emanueli, C. and Madeddu, P. (2008) Diabetes and vessel wall remodelling: From mechanistic insights to regenerative therapies. Cardiovascular Research, 78, 265-273. http://dx.doi.org/10.1093/cvr/cvn039

[54] Tengi, M., Geng, Z., Huang, L. and Zhao, X. (2012) Stem cell transplantation in cardiovascular disease: An update. Journal of International Medical Research, 40, 833-838. http://dx.doi.org/10.1177/147323001204000301

[55] Leeper, N.J., Hunter, A.L. and Cooke, J.P. (2010) Stem cell therapy for vascular regeneration. Adult, embryonic, and induced pluripotent stem cells. Circulation, 122, 517526.

http://dx.doi.org/10.1161/CIRCULATIONAHA.109.8814 $\underline{41}$

[56] Okita, K., Ichisaka, T. and Yamanaka, S. (2007) Generation of germline-competent induced pluripotent stem cells. Nature, 448, 313-317. http://dx.doi.org/10.1038/nature05934

[57] Okita, K., Nakagawa, M., Hyenjong, H., Ichisaka, T. and Yamanaka, S. (2008) Generation of mouse induced pluripotent stem cells without viral vectors. Science, 322, 949953. http://dx.doi.org/10.1126/science.1164270

[58] Sommer, C.A., Stadtfeld, M., Murphy, G.J., Hochedlinger, K., Kotton, D.N. and Mostoslavsky, G. (2009) Induced pluripotent stem cell generation using a single lentiviral stem cell cassette. Stem Cells, 27, 543-549. http://dx.doi.org/10.1634/stemcells.2008-1075

[59] Stadtfeld, M., Nagaya, M., Utikal, J., Weir, G. and Hochedlinger, K. (2008) Induced pluripotent stem cells generated without viral integration. Science, 322, 945-949. http://dx.doi.org/10.1126/science.1162494
[60] Huangfu, D., Osafune, K., Maehr, R., Guo, W., Eijkelenboom, A., Chen, S., Muhlestein, W. and Melton, D.A. (2008) Induction of pluripotent stem cells from primary human fibroblasts with only Oct4 and Sox2. Nature Biotechnology, 26, 1269-1275. http://dx.doi.org/10.1038/nbt.1502

[61] Nishikawa, S., Goldstein, R.A. and Nierras, C.R. (2008) The promise of human induced pluripotent stem cells for research and therapy. Nature Reviews Molecular Cell Biology, 9, 725-729. http://dx.doi.org/10.1038/nrm2466

[62] Park, I.H., Lerou, P.H., Zhao, R., Huo, H. and Daley, G.Q. (2008) Generation of humaninduced pluripotent stem cells. Nature Protocols, 3, 1180-1186. http://dx.doi.org/10.1038/nprot.2008.92

[63] Tatard, V.M., Venier-Julienne, M.C., Saulnier, P., Prechter, E., Benoit, J.P., Menei, P. and Montero-Menei, C.N. (2005) Pharmacologically active microcarriers: A tool for cell therapy. Biomaterials, 26, 3727-3737. http://dx.doi.org/10.1016/j.biomaterials.2004.09.042

[64] Prakash, S., Khan, A. and Paul, A. (2010) Nanoscaffold based stem cell regeneration therapy: Recent advancement and future potential. Expert Opinion on Biological Therapy, 10, 1649-1661. http://dx.doi.org/10.1517/14712598.2010.528387

[65] Madonna, R. and De Caterina, R. (2011) Stem cells and growth factor delivery systems for cardiovascular disease. Journal of Biotechnology, 154, 291-297. http://dx.doi.org/10.1016/j.jbiotec.2011.05.014

[66] Trounson, A., DeWitt, N.D. and Feigal, E.G. (2012) The Alpha Stem Cell Clinic: A model for evaluating and delivering stem cell-based therapies. Stem Cells Translational Medicine, 1, 9-14. http://dx.doi.org/10.5966/sctm.2011-0027 